\title{
EDITORIAL
}

\section{Relevancia y sentido del Consejo de la Revista Chilena de Salud Pública}

La Revista Chilena de Salud Pública ha considerado necesario tener en su estructura la presencia de un Consejo, constituido por 21 profesionales de los más variados ámbitos de la salud y de otras disciplinas científicas, que han contribuido a enriquecer la reflexión, investigación y aplicación de los fundamentos esenciales de una salud pública basada en evidencias, entendida ésta como el "uso informado, explícito y juicioso de la evidencia obtenida por una amplia gama de investigaciones científicas y sociales, además de los métodos de evaluación de acciones, intervenciones y/o programas de salud colectiva". Así comprendida la acción de la salud pública, una revista dedicada a poner en conocimiento de la comunidad científica la investigación primaria en el campo de la salud colectiva, requería contar con un grupo amplio de personas, que desde las perspectivas particulares de sus disciplinas, actividades laborales, valores y experiencias, pudiesen entregar a la misión de la revista el "consejo" oportuno para evitar un reduccionismo cientificista, que pudiese privilegiar la profundidad del detalle sacrificando la riqueza de los contextos sociales que rodean a todas las actividades de la salud pública.

De la misma forma, el Consejo de la RCHSP es un esfuerzo por reunir las visiones coincidentes o discrepantes de la misión de una revista como la nuestra, que pueden provenir desde el trabajo académico, del realizado en actividades de servicios de salud o del arduo terreno del decidor de políticas; estos diversos puntos de vista contribuyen a una mayor integralidad de la misión de la revista, sin perder su prestancia científica, muy por el contrario enriqueciéndola.

Los integrantes del Consejo de la RCHSP, además de su destacada trayectoria en la salud pública nacional, provienen de instituciones de diversa índole, relacionadas, por cierto, a la salud en general y a la salud pública en particular, instituciones que a través de los consejeros transmiten sus propias perspectivas, pero en un escenario de respeto, pluralidad y estricta observancia de la naturaleza científica de una revista que aspira a ser vehiculo de expresión y fuente de estímulo para mejorar la investigación en salud pública en nuestro país.

Debemos destacar en la composición del Consejo, la concurrencia de profesionales de diversas regiones del país. Este es otro elemento importante para una revista de salud pública, que en el escenario homogenizador de la modernidad y de centralismos no justificados, tiene muy clara la necesidad de no olvidar las peculiaridades en salud colectiva de las diversas comunidades, pueblos y culturas que existen en nuestro país. La variedad de investigaciones epidemiológicas que nos llegan para optar a su publicación en la RCHSP se encarga de mostrárnosla.

Del mismo modo, trabajos y experiencias de investigadores en gestión y administración de salud, nos señalan algo que por conocido se tiende a olvidar: los recursos disponibles para la atención de salud, no están equitativamente distribuidos y las decisiones de políticas públicas en salud excesivamente centralizadas, conducen a una comprobación desalentadora sobre la participación efectiva de personas y colectividades, lo que es a veces sólo un discurso, y no siempre se consideran de manera apropiada las variaciones ambientales, de costumbres, de valores y de determinantes sociales que se expresan en las comunidades que habitan nuestro país. 
Por tal motivo, el Consejo de la RCHSP constituido por profesionales, académicos e investigadores provenientes de diversos instituciones de fuera de la Región Metropolitana, permiten estimular la afluencia de trabajos de diversas zonas de nuestro país y permiten a la RCHSP y, especialmente, a su Comité Editorial, estar atentos a promover el envío de investigaciones de grupos locales, que con esfuerzo y calidad generan un conocimiento científico de las diversas realidades sanitarias de Chile.

Finalmente, la RCHSP, agradece a los consejeros su participación desinteresada e intelectualmente provocadora. Se trata de personas de gran capacidad y trayectoria profesional, reconocida nacional e internacionalmente, que participan frecuentemente en encuentros científicos de alto nivel, publican su trabajos en revistas de alto impacto o desarrollan asesorías o consultorías internacionales. Lo anterior, les permite que, desde su función de consejería, señalen tanto al Comité Ejecutivo como al Comité Editorial de la Revista Chilena de Salud Pública, parámetros de la más alta exigencia para una revista científica, orientando su desarrollo con altos estándares de calidad, imprescindibles para una revista de esta naturaleza, que se ha propuesto contribuir a un franco mejoramiento de la investigación en salud pública nacional. Y, desde ese punto de partida, constituirse en una publicación que investigadores especialmente de países de la región latinoamericana y el Caribe, reconozcan como un medio de significación e impacto para publicar su producción científica. El Consejo de la RCHSP es un factor decisivo para ello. 